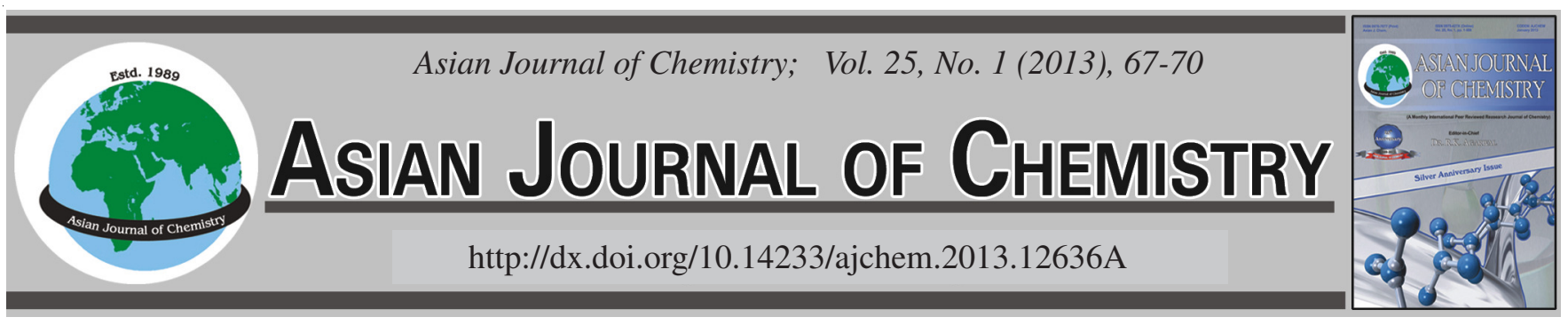

\title{
Microwave Synthesis of Ag-CdWO$/$ /Zeolite Composites Assisted by A Solid-State Metathetic Route
}

\author{
Chang Sung Lim
}

Department of Advanced Materials Science \& Engineering, Hanseo University, Seosan 356-706, South Korea

Corresponding author: Tel/Fax: +82 41 6601445; E-mail: cslim@ hanseo.ac.kr

$\mathrm{Ag}-\mathrm{CdWO}_{4} /$ zeolite-A porous composites were synthesized using a solid-state metathetic (SSM) method with microwave irradiation. The characteristics of the solid-state metathetic reaction and the formation of the high lattice energy by-product $\mathrm{NaCl}$ were found to drive the reaction for Wolframite-type $\mathrm{CdWO}_{4}$ toward completion. The $\mathrm{Ag}-\mathrm{CdWO}_{4} /$ zeolite-A porous composites were formed completely at $600{ }^{\circ} \mathrm{C}$. Monoclinic-like crystals of $\mathrm{CdWO}_{4}$ were primarily co-mixed with porous zeolite-A. Small spherical silver particles were immobilized in the porous $\mathrm{CdWO}_{4}$ /zeolite-A matrix.

Key Words: Microwave synthesis, Solid-state metathetic, Ag-CdWO $4 /$ zeolite.

\section{INTRODUCTION}

Cadmium tungstate $\left(\mathrm{CdWO}_{4}\right)$ is considered to be an attractive materials because of its optical, chemical and structural properties. It is well known that $\mathrm{CdWO}_{4}$ crystals with Wolframite structures have high thermal stability, high average refractive index, low radiation damage, low intrinsic background, low after growing and high X-ray absorption. They can be used in spectrometry and radiometry of radionuclide in extra-low activities ${ }^{1}$. $\mathrm{CdWO}_{4}$ has a Wolframite-type crystal structure with lattice parameters of $\mathrm{a}=5.03 \AA$ and $\mathrm{b}=$ $5.86 \AA$ and $\mathrm{c}=5.07 \AA$ and $\beta=91.47^{\circ 2}$. The $\mathrm{CdWO}_{4}$ easily forms relatively thin structures due to its intrinsic (010) cleave plane because of the chain structure of the $\left[\mathrm{WO}_{6}\right]^{6-}$ octahedra in the Wolframite-type structure. The self-assembled rod-like and various short rod-like morphology of $\mathrm{CdWO}_{4}$ are constructed with several submicron-rods attaching for their arrangements. Cadmium tungstate has attracted extensive attention because of their particular importance in investigating the sizes and shape-dependent properties as well as their immobilization in porous materials for potential applications. For tungstate materials to be used for practical applications, versatile characteristics are required for the particle size distribution and morphology of the particles. The well-defined particle features of the $\mathrm{Ag}-\mathrm{CdWO} /$ /zeolite-A porous composites are required for the immobilization features for potential applications ${ }^{3-7}$.

In recent years, the processes of $\mathrm{CdWO}_{4}$ are prepared by a range of processes, such as a solid-state reaction ${ }^{8,9}$, coprecipitation $^{10-12}$, a molten salt method ${ }^{13,14}$, a hydrothermal reaction $^{15,16}$, a combustion method ${ }^{17}$, a microwave synthesis ${ }^{17-22}$. Solid-state metathetic reactions involve the exchange of atomic/ionic species, where the driving force is the exothermic reaction accompanying the formation of $\mathrm{NaCl}$ with high lattice energy. Solid-state metathetic reactions occur so rapidly that the exothermic reaction is essentially used to heat the solid products. Solid-state synthesis of materials by the metathetic route is a simple method of synthesis, cost-effective, high yield and easy scale up and is emerging as a viable alternative approach for synthesizing high-quality novel inorganic materials in a short time $\mathrm{e}^{23,24}$. The solid-state metathetic approach assisted by microwave irradiation has been applied successfully to the synthesis of metal tungstates of Wolframite-type 25-29. $^{2}$. $\mathrm{Ag}$-incorporated $\mathrm{CdWO}_{4} /$ zeolite-A porous composites are expected to have excellent adsorption and synergy effects in an immobilization mechanism of metallic catalysts for a wide range of applications, such as sensors, photocatalysts, luminescence, antibacterial matrices and optical effects in the UV and visible region.

In present study, $\mathrm{Ag}-\mathrm{CdWO}_{4} /$ zeolite-A porous composites were synthesized using a solid-state metathetic method with microwave irradiation. The characteristics of the solid-state metathetic reaction and the formation of a high lattice energy by-product $\mathrm{NaCl}$ were discussed. The $\mathrm{Ag}-\mathrm{MnWO}_{4} /$ zeolite-A porous composites were immobilized from mixed metathetic precursors at moderate temperatures. The crystallization process, thermal decomposition and morphology of the synthesized Ag-CdWO $4 /$ zeolite-A porous composite powders were evaluated. 


\section{EXPERIMENTAL}

Fig. 1 shows a flow chart for the synthesis of $\mathrm{Ag}-\mathrm{CdWO}_{4} /$ zeolite-A porous composites from the solid-state metathetic method using microwave irradiation. $\mathrm{CdCl}_{2} \cdot 2.5 \mathrm{H}_{2} \mathrm{O}$ and $\mathrm{Na}_{2} \mathrm{WO}_{4} \cdot 2 \mathrm{H}_{2} \mathrm{O}$ were used to prepare the cadmium tungstate compound. The preparation of cadmium tungstates was carried out by reacting well-ground mixtures of $\mathrm{CdCl}_{2} \cdot 2.5 \mathrm{H}_{2} \mathrm{O}$ and $\mathrm{Na}_{2} \mathrm{WO}_{4} \cdot 2 \mathrm{H}_{2} \mathrm{O}$ for $\mathrm{CdWO}_{4}$ at a molar ratio of $1: 1$. The sample mixtures were dried at $100{ }^{\circ} \mathrm{C}$ for $12 \mathrm{~h}$ and $5 \mathrm{wt} \%$ $\mathrm{AgNO}_{3}$ and $25 \mathrm{wt} \%$ synthetic zeolite-A were then added. The samples were placed into crucibles and exposed to domestic microwave (Samsung Electronics Corp. Korea) operating at a frequency of $2.45 \mathrm{GHz}$ and a maximum out-put power of 1250 $\mathrm{W}$ for $10 \mathrm{~min}$. The samples were treated with ultrasonic radiation and washed many times with distilled water and ethanol to remove the sodium chloride reaction by-product. The samples were dried at $100^{\circ} \mathrm{C}$ in an oven. Heat-treatment of the samples was performed at $600^{\circ} \mathrm{C}$ for $3 \mathrm{~h}$.

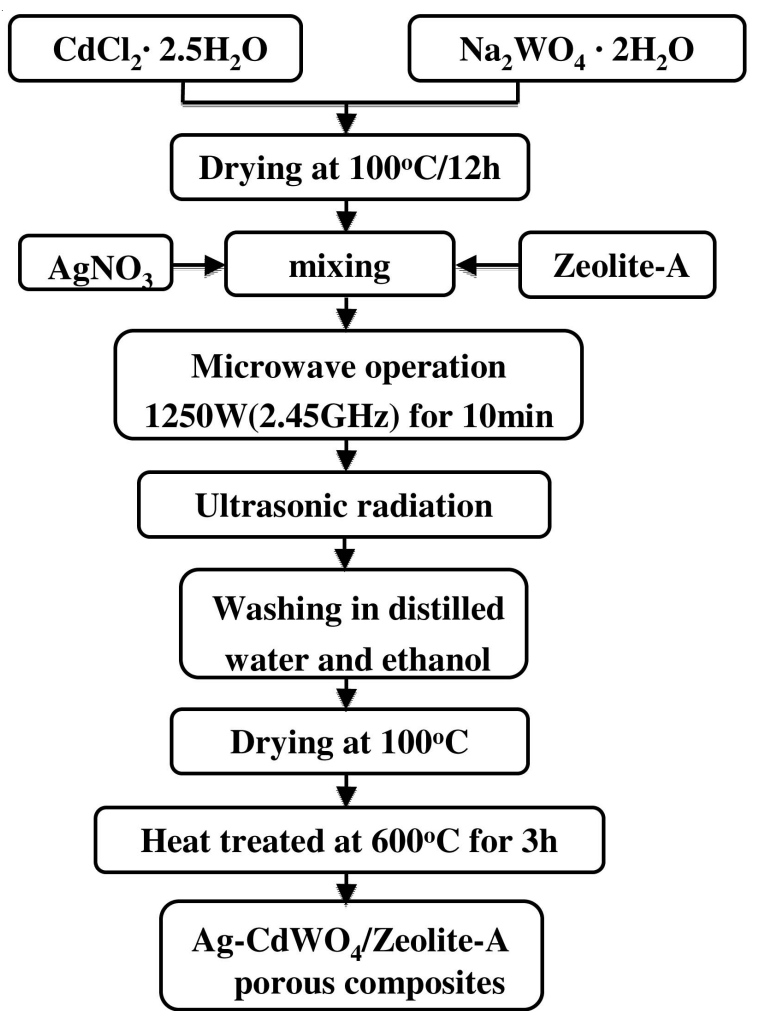

Fig. 1. Flow chart for the synthesis of $\mathrm{Ag}_{-} \mathrm{CdWO} / \mathrm{zeolite}-\mathrm{A}$ porous composites from the solid-state metathetic method using microwave irradiation

The phase existings in the particles after the solid-state metathetic reactions and heat-treatment were identified by XRD (D/MAX 2200, Rigaku, Japan). FTIR (Nicolet IR200, Thermo Electron corporation, USA) was used to examine the thermal-decomposition behaviour of the solid-state metathetic reaction and the obtained particles over the frequency range, 4000 to $400 \mathrm{~cm}^{-1}$. The microstructure and surface morphology of the $\mathrm{Ag}-\mathrm{CdWO}_{4} /$ zeolite-A porous composite powders were observed by scanning electron microscopy (JSM-5600, JEOL, Japan) and energy-dispersive X-ray spectroscopy (EDS).

\section{RESULTS AND DISCUSSION}

Fig. 2 shows FT-IR spectra of the Ag-CdWO $4 /$ zeolite-A porous composites after (a) solid-state metathetic reaction $(\mathrm{Ag}-\mathrm{CdWO}-\mathrm{Z}-\mathrm{m})$ and (b) heat-treated at $600{ }^{\circ} \mathrm{C}$ for $3 \mathrm{~h}$ (Ag-CdWO $-\mathrm{Z}-\mathrm{m600)}$. The absorption bands at 473 and 532 $\mathrm{cm}^{-1}$ can be assigned to symmetric and asymmetric deformation mode of $\mathrm{Cd}-\mathrm{O}$ in $\mathrm{CdO}_{6}$ octahedra. The absorption bands with their maxima at 633 and $710 \mathrm{~cm}^{-1}$ can be due to the stretching modes of $\mathrm{W}-\mathrm{O}$ in $\mathrm{WO}_{6}$ octahedra. The bands at 834 and 877 $\mathrm{cm}^{-1}$ were due to symmetrical vibrations of bridge oxygen atoms of the Cd-O-W groups. The small band at 1450, 1630, $3400 \mathrm{~cm}^{-1}$ can in Fig. 2(a) Ag-CdWO $-\mathrm{Z}-\mathrm{m}$ are assigned to the $\mathrm{HOH}$ bending vibrations. It is assumed that the samples prepared contain a significant amount of surface-adsorbed water and alcohol.

(b) $\mathrm{Ag}-\mathrm{CdWO}_{4}-\mathrm{Z}-\mathrm{m} 600$

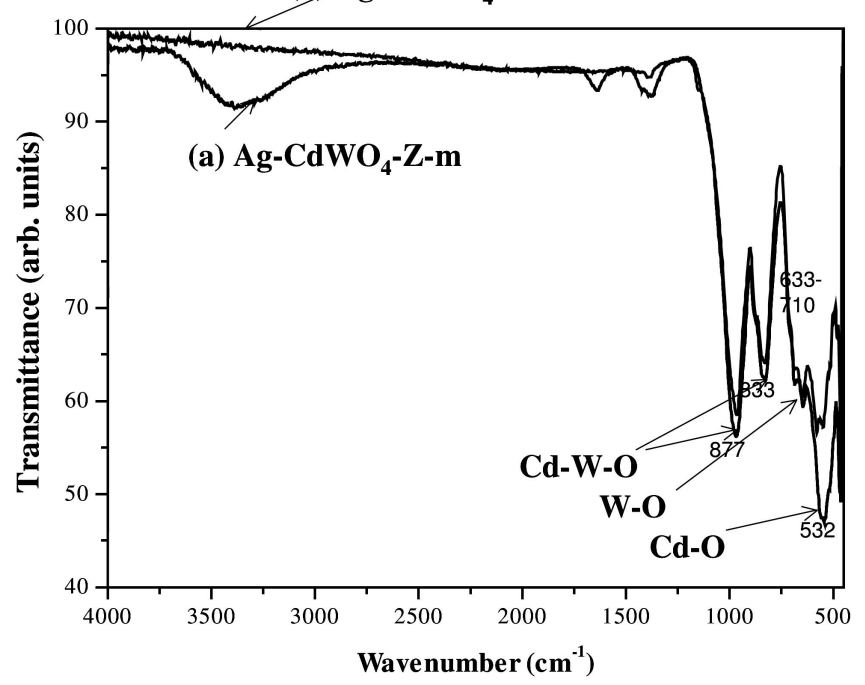

Fig. 2. FT-IR spectra of the $\mathrm{Ag}-\mathrm{CdWO}_{4} /$ zeolite-A porous composites after (a) solid-state metathetic reaction and (b) heat-treatment at $600{ }^{\circ} \mathrm{C}$ for $3 \mathrm{~h}$

Fig. 3 shows SEM images of the Ag-CdWO $4 /$ zeolite-A porous composites after (a)/(b) solid-state metathetic reaction and (c)/(d) heat-treated at $600{ }^{\circ} \mathrm{C}$ for 3 h. Fig. 3(a) and (b) shows SEM images of the $\mathrm{Ag}-\mathrm{CdWO}_{4} /$ zeolite-A porous composites synthesized by solid-state metathetic reaction after removing the $\mathrm{NaCl}$. $\mathrm{CdWO}_{4}$ crystallizes in Wolframite crystal structures. Presence of sodium chloride confirms the reaction has proceeded in solid-state metathesis way. Parhi et al. ${ }^{25}$ reported the microwave metathetic synthesis of various metal tungstates and showed that microwave radiation provided the energy required to overcome the energy barrier that precludes a spontaneous reaction and helped heat the bulk of the material uniformly, resulting in fine particles with a controlled morphology and the formation of the product in a green manner without the generation of solvent waste.

In Fig. 3(c) and (d), the SEM images of Ag-CdWO $/$ zeolite-A porous composites after solid-state metathetic reaction and followed by heat-treatment at $600^{\circ} \mathrm{C}$ for $3 \mathrm{~h}$ show the well crystallized $\mathrm{CdWO}_{4}$ on the zeolite-A synthesized by a solid-state metathetic reaction. The monoclinic-like crystals of $\mathrm{CdWO}_{4}$ were primarily co-mixed with $\mathrm{Ag}$ on the porous 

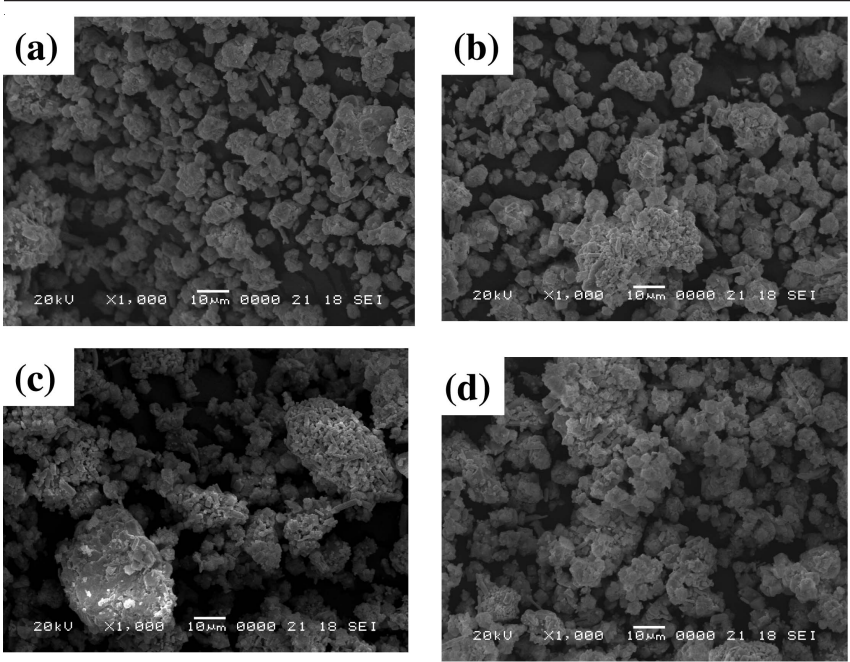

Fig. 3. SEM images of the Ag-CdWO $4 /$ zeolite-A porous composites after (a) and (b) solid-state metathetic reaction and (c) and (d) heattreatment at $600{ }^{\circ} \mathrm{C}$ for $3 \mathrm{~h}$

zeolite-A surfaces. The spherical small particles of silver were well immobilized in the porous $\mathrm{CdWO}_{4} /$ zeolite-A composites matrix. Solid state metathesis reactions, such as $\mathrm{ACl}_{2}+\mathrm{Na}_{2} \mathrm{WO}_{4}$ $\longrightarrow \mathrm{AWO}_{4}+2 \mathrm{NaCl}$, involves the exchange of atomic/ionic species, where the driving force is the formation of thermodynamically stable alkali or alkaline earth halides with high lattice energy. The thermodynamic basis for such metathetic reactions has been reported ${ }^{25,30-32}$. Parhi et al. ${ }^{25-28}$ calculated the enthalpy $(\Delta \mathrm{H})$ and free energy change $(\Delta \mathrm{G})$ associated with the formation of tungstates and reported $\Delta \mathrm{H}=-36.17$ $\mathrm{KJ} / \mathrm{mol}$ for $\mathrm{ZnWO}_{4}$ showing that both the enthalpy change favours the metathesis reaction and the enthalpy change is indeed the driving force for the metathesis involving the formation of $\mathrm{NaCl}$. Solid-state metathetic reactions occur so rapidly that all the enthalpy released is essentially used to heat up the solid products, usually raising the alkali halide near or above its normal boiling point and have been recognized to be approximately adiabatic in nature ${ }^{33}$.

Fig. 4 shows (a) EDS patterns, (b) quantitative compositions, (c) a SEM image and (d) quantitative results of the synthesized Ag-CdWO 4 /zeolite-A porous composites at $600{ }^{\circ} \mathrm{C}$ for $3 \mathrm{~h}$. The EDS patterns and quantitative compositions of the synthesized $\mathrm{Ag}-\mathrm{CdWO}_{4} /$ zeolite-A porous composites were composed of $\mathrm{Ag}, \mathrm{CdWO}_{4}$ and zeolite-A.

For tungstate materials to be used for practical applications, versatile characteristics are required for the particle size distribution and morphology of the particles. The welldefined particle features of the $\mathrm{Ag}-\mathrm{CdWO}_{4} /$ zeolite-A porous composites synthesized by solid-state metathetic reactions have control over the morphology of the final particles and can be used for such technological applications. Owing to the enthalpy change by the driving force for the metathetic formation of $\mathrm{NaCl}$, the solid-state metathetic reactions affect not only the

(a)

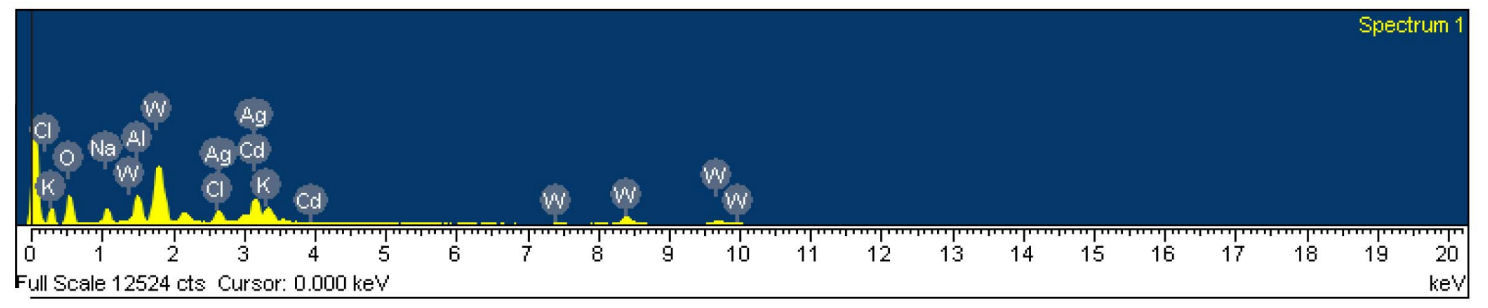

(b)

\begin{tabular}{l|llllllllll}
\hline Spectrum & In stats. & $\mathrm{O}$ & $\mathrm{Na}$ & $\mathrm{Al}$ & $\mathrm{Cl}$ & $\mathrm{K}$ & $\mathrm{Ag}$ & $\mathrm{Cd}$ & $\mathrm{W}$ & Total \\
Spectrum 1 & Yes & 33.04 & 5.07 & 5.66 & 3.47 & 1.35 & 5.77 & 16.30 & 29.35 & 100.00 \\
Mean & & 33.04 & 5.07 & 5.66 & 3.47 & 1.35 & 5.77 & 16.30 & 29.35 & 100.00 \\
Std. deviation & & 0.00 & 0.00 & 0.00 & 0.00 & 0.00 & 0.00 & 0.00 & 0.00 & \\
Max. & & 33.04 & 5.07 & 5.66 & 3.47 & 1.35 & 5.77 & 16.30 & 29.35 & \\
Min. & & 33.04 & 5.07 & 5.66 & 3.47 & 1.35 & 5.77 & 16.30 & 29.35 & \\
\hline
\end{tabular}

(c)

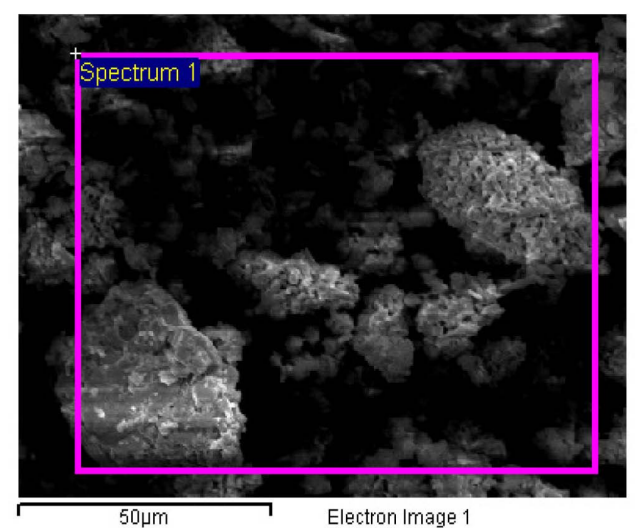

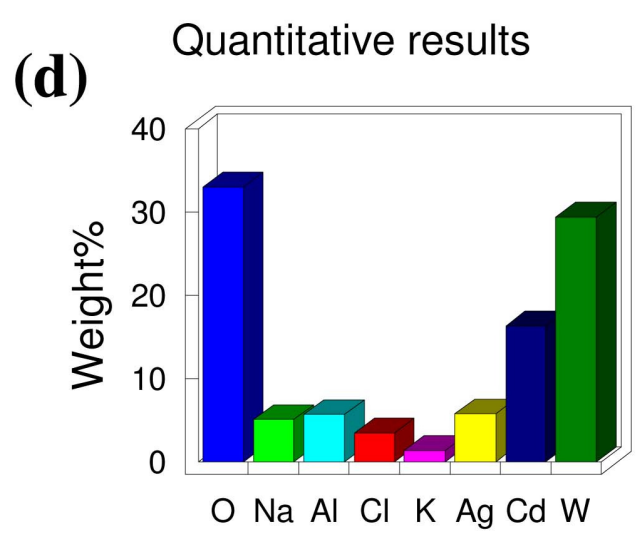

Fig. 4. EDS patterns (a), quantitative compositions (b), a SEM image (c) and quantitative results (d) of the synthesized $\mathrm{Ag}_{-} \mathrm{CdWO}_{4} /$ zeolite-A porous composites 
morphology of the $\mathrm{CdWO}_{4}$ particles, but also the formation of functional zeolite and $\mathrm{Ag}$ immobilized in the porous composite matrix. Therefore, a variation of metathetic reactions of $\mathrm{CdCl}_{2}$ $+\mathrm{Na}_{2} \mathrm{WO}_{4} \longrightarrow \mathrm{CdWO}_{4}+2 \mathrm{NaCl}$ is required to control the well-defined particle features of the $\mathrm{Ag}-\mathrm{CdWO}_{4} /$ zeolite-A porous composites.

\section{Conclusion}

$\mathrm{Ag}-\mathrm{CdWO} /$ /zeolite-A porous composites were synthesized using solid-state metathetic method with microwave irradiation. The Ag-CdWO${ }_{4} /$ zeolite-A porous composites at $600{ }^{\circ} \mathrm{C}$ for $3 \mathrm{~h}$ were completed entirely at $600^{\circ} \mathrm{C}$. The well crystallized $\mathrm{CdWO}_{4}$ on the zeolite-A synthesized by a solid-state metathetic reaction. The monoclinic-like crystals of $\mathrm{CdWO}_{4}$ were primarily co-mixed with Ag on the porous zeolite-A surfaces. The spherical small particles of silver were well immobilized in the porous $\mathrm{CdWO}_{4} /$ zeolite-A composites matrix. The enthalpy change favours the metathesis reaction and the enthalpy change is indeed the driving force for the metathesis involving the formation of $\mathrm{NaCl}$. Solid-state metathetic reactions occur so rapidly that all the enthalpy released is essentially used to heat up the solid products of $\mathrm{Ag}-\mathrm{CdWO}_{4} /$ zeolite-A porous composites.

\section{ACKNOWLEDGEMENTS}

This study was supported by Basic Science Research Program through the National Research Foundation of Korea (NRF) funded by the Ministry of Education, Science and Technology (2011-0026911).

\section{REFERENCES}

1. S. Rajagopal, D. Nataraj, O.Y. Khyzhun, Y. Djaoued, J. Robichaud and D. Mangalaraj, J. Alloys Comp., 493, 340 (2010).

2. S. Rajagopal, V.L. Bekenev, D. Nataraj, D. Mangalaraj and O.Y. Khyzhun, J. Alloys Comp., 496, 61 (2010).

3. X. Cao, W. Wu, N. Chen, Y. Peng and Y. Liu, Sens. Actuators B, 137, 83 (2009).

4. C. Yu and J.C. Yu, Mater. Sci. Eng. B, 164, 16 (2009).

5. S. Lin, J. Chen, X. Weng, L. Yang and X. Chen, Mater. Res. Bull., 44, 1102 (2009)
6. P.K. Pandy, N.S. Bhave and R.B. Kharat, J. Mater. Sci., 42, 7927 (2007).

7. R.P. Jia, G.X. Zhang, Q.S. Wu and Y.P. Ding, Mater. Lett., 61, 1793 (2007).

8. S.M. Montemayeor and A.F. Fuentes, Ceramics Int., 30, 393 (2004).

9. S.J. Naik and A.V. Salker, Solid State Sci., 12, 2065 (2010).

10. T. Montini, V. Gombac, A. Hameed, L. Felisari, G. Adami and P. Fornasiero, Chem. Phys. Lett., 498, 113 (2010).

11. T. You, G. Cao, X. Song, C. Fan, W. Zhao, Z. Yin and S. Sun, Mater. Lett., 62, 1169 (2008).

12. A. Sen and P. Pramanik, J. Eur. Ceramics Soc., 21, 745 (2001).

13. Z. Song, J. Ma, H. Sun, W. Wang, Y. Sun, L. Sun, Z. Liu and C. Gao, Ceramics Int., 35, 2675 (2009).

14. Z. Song, J. Ma, H. Sun, Y. Sun, J. Fang, Z. Liu, C. Gao, Y. Liu and J. Zhao, Mater. Sci. Eng. B, 163, 62 (2009)

15. D. Chen, G. Shen, K. Tang, H. Zheng and Y. Qian, Mater. Res. Bull, 38, 1783 (2003).

16. L. Zhen, W.S. Wang, C.Y. Xu, W.Z. Shao and L.C. Qin, Mater. Lett., 62, 1740 (2008).

17. S.L. Gonzalez-Cortes, T.C. Xiao, P.M.F.J. Costa, S.M.A. Rodulfo-Baechler and M.L.H. Green, J. Mol. Catal. A, 238, 127 (2005).

18. K.J.D. MacKenzie, J. Temuujin, C. McCammon and M. Senna, J. Eur. Ceramics Soc., 26, 2581 (2006).

19. A.L.M. de Oliveira, J.M. Ferreira, M.R.S. Silva, S.C. de Souza, F.T.G. Vieira, E. Longo, A.G. Souza and I.M.G. Santos, J. Therm. Anal. Calorim., 97, 167 (2009).

20. J.T. Kloprogge, M.L. Weier, L.V. Duong and R.L. Frost, Mater. Chem. Phys., 88, 438 (2004).

21. J.H. Ryu, C.S. Lim, W.C. Oh and K.B. Shim, J. Ceram. Proc. Res., 5, 316 (2004).

22. J. Bi, L. Wu, Z. Li, Z. Ding, X. Wang and X. Fu, J. Alloys Comp., 480, 684 (2009).

23. S. Das, A.K. Mukhopadhyay, S. Datta and D. Basu, Bull. Mater. Sci., 32, 1 (2009).

24. K.P.F. Siqueira, R.L. Moreira, M. Valadares and A. Dias, J. Mater. Sci., 4, 6083 (2010)

25. P. Parhi, T.N. Karthik and V. Manivannan, J. Mater. Sci., 465, 380 (2008).

26. P. Parhi and V. Manivannan, J. Eur. Ceramics Soc., 28, 1665 (2008).

27. P. Parhi and V. Manivannan, J. Alloys Comp., 469, 558 (2009).

28. P. Parhi, S.S. Singh, A.R. Ray and A. Ramanan, Bull. Mater. Sci., 29, 115 (2006).

29. V. Thangadurai, C. Knittlmayer and W. Weppner, Mater. Sci. Eng. B, 106, 228 (2004).

30. E.G. Gillan and R.B. Kanar, Chem. Mater, 8, 333 (1996).

31. J.J. Mack, S. Tari and R.B. Kaner, Inorg. Chem., 45, 4243 (2006).

32. A.M. Nartowski, I.P. Parkin, M. Mackenzie, A.J. Craven and I. MacLeod, J. Mater. Chem., 9, 1275 (1999).

33. T.K. Mandal and J. Gopalakrishnan, J. Mater. Chem., 14, 1273 (2004). 